\title{
К ВОПРОСУ ИСПОЛЬЗОВАНИЯ БАЗОВЫХ ПРИНЦИПОВ ФОРСАЙТА ДЛЯ РЕШЕНИЯ СЛОЖНЫХ ТЕКУЩИХ ПРОБЛЕМ ЗДРАВООХРАНЕНИЯ
}

\author{
(ㄷ) 2021 Стерликов Федор Павлович \\ аспирант МГУТУ, главный специалист \\ Научно-исследовательский институт организации здравоохранения и медицинского менеджмента \\ Департамента здравоохранения города Москвы, Россия, Москва \\ E-mail: niiozmm@zdrav.mos.ru \\ (c) 2021 Стерликов Федор Федорович \\ доктор экономических наук, профессор, \\ лауреат премии Правительства Российской Федерации в области науки и техники \\ Московский государственный университет технологий и управления имени К. Г. Разумовского \\ (Первый казачий университет), Россия, Москва \\ E-mail: OET2004@yandex.ru
}

Исследуются возможности использования базовых принципов Форсайта для получения организационно-методологической информации, необходимой для принятия оперативных и долгосрочных решений на всех уровнях.

Ключевые слова: Форсайт, метода Дельфи, технологично ориентированный Форсайт, прогнозирование будущего для всего общества.

Форсайт - это взаимодействие ответственных лиц и организаций по поводу достижения будущих целей.

Практика организации и управления всех сфер общественной жизни заинтересована в получении рекомендаций по прогнозированию будущего. Новый подход, разработанный компанией RAND, быстро стал применяться всем мире. И не случайно интерес ученых за последние годы, можно сказать, увеличился в геометрической прогрессии, если судить по публикациям о Форсайте и применяемым методам прогнозирования (табл. 1).

Под Форсайтом («Foresight») в первое время понималось новейшая технология, которая позволяла шире учитывать социальные ценности при планировании общественных решений (права человека, свобода совести, слова, убеждений, верования, свобода политического выбора, национальный суверенитет). Технология Фор-

сайта предполагает привлечение к планированию выделенной проблемы всех, кто участвует в производстве и потреблению создаваемого товара или услуги. Таким образом удается в большой мере учесть интересы потребителей и возможности производителей. При этом не просто суммируются предвидения участников, а обсуждаются их предложения и аргументации предложений, желательно апробированных в реальной действительности.

Несколько слов о истории становлении Форсайта как новейшей технологии предвидения.

Интерес людей к будущему всегда существовал, вне зависимости от времен и идеологий. Они всегда будут готовы использовать предсказания, прогнозы, опираться в своей деятельности на футурологический экскурс и с удовольствием грезить фантастикой. В Советском Союзе использовались элементы предвидения в оборонной промышленности, например, для реше-

Таблица 1. Количество публикаций о Форсайте

\begin{tabular}{|c|c|}
\hline Десятилетие & Количество публикаций, примерно \\
\hline $1960-1969$ гг. & 300 \\
\hline $1970-1970$ гг & 800 \\
\hline $1980-1989$ гг. & 2000 \\
\hline $1990-1999$ гг & 3000 \\
\hline $2000-2012$ гг & 8000 \\
\hline
\end{tabular}

По данным К. О. Вишневского 
Таблица 2. Методы, применяемые в различных отраслях и сферах

\begin{tabular}{|l|l|}
\hline \multicolumn{1}{|c|}{ Сферы общественной жизни } & \multicolumn{1}{|c|}{ Применяемые методы прогнозирования } \\
\hline Энергетика & Сценарии \\
\hline Транспорт и коммуникации & Дельфи, экспертные панели, сценарии междисциплинарный анализ \\
\hline Области экономики & Сценарии \\
\hline Социальная сфера & Анализ литературы, многокритериальный и структурный анализ \\
\hline Экология & Дорожная карта, экспертные панели, сценарии, семинары \\
\hline Наука, технологическое развитие & Интервью, обследовании, анализ литературы, бенчмаркетинг \\
\hline Междисциплинарный характер & Экспертные панели, сценарии, индикаторы, SWOT-анализ \\
\hline
\end{tabular}

По данным К. О. Вишневского

ния проблемы завоевания лидерства в космосе.

Основное внимание современными учеными и практиками уделяется технологии Форсайта, содержащей как разнообразные методики и инструментарии предвидения, применяемыми в различных отраслях и сферах общественной жизни (табл. 2).

Более подробное значение предлагаемых методов рассмотрены дальше.

Метод Дельфи - поиск решений основывается на обобщении мнений и позиций группы специалистов, высказанных в процессе предварительно проведенной мозговой атаки, а также с учетом экспертных оценок.

Сценирование - технология выработки стратегии, включающей разработку нескольких сценариев, возможных при реализации поставленной задачи, реализуемых в определенных условиях.

SWOT-анализ - метод базируется на выявлении сильных и слабых сторон, проявляющихся при решении проблемы:

S (strengths) - учет сильных сторон: преимуществ, особых ценностей, уникальных навыков. Другими словами, учет всего, что положительно влияет на увеличение продаж, закрепление на рынке, повышает уверенность в конкурентной борьбе;

W (weaknesses) - учет слабых сторон: причины проигрыша конкурентам, тормозящих рост прибыли, мешающих развитию;

O (opportunities) - учет возможностей, т.е. всего того, что. находится в руках бизнеса и поддаётся прямому воздействию (повышение квалификации сотрудников и прочее);

$\mathrm{T}$ (threats) - учет угроз от внешних факторов и от принимаемых вами решений.

Мозговые штурмы - деловые совещания по принятию инновационных коллективных управленческих решений, которые стимулируют творческую активность участников совещания.

Обзор литературы- анализ использованной литературы, формулировок основных идей, тенденций, использования, выявление теоретической базы исследования

Анализ патентов - проводят для: определения технического уровня и тенденций развития в области техники, определения новизны и изобретательский уровень предполагаемого технического решения;

Переговорные игры - формируется два варианта сценария ведения переговоров, на безе которых выявляются позиции соперничающих стороны.

Дорожные карты - дают представление о временном и содержательном этапах решения проблемы. Они составляются только после проведения основательного анализа, когда просматривается образ результата применяемых мероприятий.

Пришло время вспомнить про важность стратегического планирования, использования Форсайта в вопросах обеспечения медицинских учреждений медицинскими изделиями. Во время пандемии сложно прогнозировать, все исследования перестают иметь ценность, поэтому проработать возможные сценарии будущего кажется одним из важных решений, которое может принять предприниматель.

И здесь особенно важно применение технологии Форсайта, предполагающей привлечение к планированию всех участников, задействованных в борьбе с пандемией COVID-19 (пандемией коронавирусной инфекции, вызванной коронавирусом SARS-CoV-2) [6].

По состоянию на середину марта 2021 года, зарегистрировано свыше 130 млн. случаев заболевания по всему миру; более 2,8 млн. человек скончалось.

При разработке стратеги обеспечения орга- 
низаций здравоохранения медицинскими изделиями необходимо учесть и согласовать их интересы всех участвующих в борьбе с пандемией. Поскольку Форсайт предполагает не просто обычный механизм предвидения, а обсуждение предполагаемых стратегических предложений, основанных на прогнозе явлений и процессов, вызревающих в реальной практике участников. В вопросе использования базовых принципов Форсайта для решения проблем обеспечения организаций здравоохранения медицинскими изделиями необходимо привлекать к разработке стратегии всех участников борьбы с пандемией.

В борьбе с пандемией проделана огромная работа многих отраслей народного хозяйства.

Правительством России 27 января 2020 года был создан оперативный штаб по борьбе с коронавирусной инфекцией в России во главе с заместителем председателя правительства Татьяной Голиковой. В него вошли главы многих ведомств: Минтранса, Минздрава, Роспотребнадзора, МЧС, МВД и Минпромторга. Оперативный штаб должен был оперативно мониторить ситуацию, готовить для президента доклады о результатах мониторинга ситуации и разрабатывать рекомендации по дальнейшим действиям.

14 марта 2020 года глава правительства Михаил Мишустин возглавил Координационный совет по борьбе с коронавирусом, для чего ен в ежедневном режиме вырабатывались решения и координировались действия всех ведомств по ограничению распространения коронавируса в стране.

18 марта федеральные органы власти в целях предупреждения распространения новой коронавирусной инфекции федеральными органами власти созданы ведомственные оперативные штабы.

Приняты срочнее меры по борьбе с коронавирусом:

- ограничены полеты и пересечения границ России,

- ведены карантинные ограничения,

- переведены школьники и студенты на дистанционное обучение,

- часть граждан переведена на удаленную работу,

- временно закрыты для посещения театры, музеи, цирки и другие учреждения культуры

- временно закрыты для посещения верующими религиозные учреждения,

- уточнен режим нерабочих дней,
- введен режим повышенной готовности и самоизоляции,

- введен масочный режим,

- использован пропускной режим.

Главы субъектов РФ наделены продлевать действие ограничительных мер в соответствии с эпидемиологической ситуацией в регионе.

Приняты срочные и необходимые меры по мобилизации системы здравоохранения: перепрофилирование медицинских учреждений, строительство новых и многое другое.

Введен временный порядок организации работы медицинских организаций с тем, чтобы они оперативно проводили профилактическую работу по снижению распространения коронавирусной инфекции. Создается единый номер единого колл-центра Федеральных центров для необходимой поддержки принятия решений медицинскими работниками.

Введена практика проведения дистанционных семинаров и круглосуточных консультаций для медицинских работников в регионах, проводимые специалистами НМИЦ фтизипульманологии и инфекционных заболеваний Минздрава России.

Создаются выездные мультидисциплинарные бригады для оказания организационнометодической поддержки регионам.

Проводить оперативный мониторинг ситуации с заболеваемостью COVID-19 поручено Центру стратегического планирования и управления медико-биологическими рисками здоровью. Ко времени первого пика эпидемии во всех регионах было задействовано более 184 тысяч больничных коек. В государственных и частных медицинских организациях было перепрофилировано почти 15 тысяч коек. На перепрофилирование и оснащение коек, как на федеральном, так и на региональном уровне было направлено более 76 миллиардов рублей только федерального бюджета.

Силами Министерства обороны в мае 2020 года построено 17 госпиталей в субъектах Российской Федерации. МЧС России в Мурманске развернул аэромобильные, а затем временные полевые госпитали, а также пункты временного размещения в Дагестане, Оренбургской и Самарской областях.

Медицинские вузы и другие учебные медицинские учреждения организовали подготовку и переподготовку медицинского персонала. Было подготовлено более 1,4 миллиона меди- 
цинских работников. Если в начале апреля 2020 года медицинскую помощь пациентам с новой коронавирусной инфекцией оказывали более 40 тысяч врачей, 142 тысячи среднего и 25 тысяч младшего медицинского персонала, то в июле 2020 года - 131 тысяча врачей, 272 тысячи среднего медицинского персонала и почти 63 тысячи младшего медицинского персонала.

Стране в числе первых удалось разработать диагностические тест-системы для определения новой коронавирусной инфекции, обладающие высокой аналитической чувствительностью и диагностической специфичностью. Российские разработки в этой области используются во многих странах мира.

По данным на июль 2020 года в Российской Федерации зарегистрировано 114 тест-систем для диагностики COVID-19, работали 794 лаборатории во всех регионах страны. Проведено 23,8 миллиона исследований. По уровню охвата населения тестированием на коронавирус Россия занимает второе место в мире. РФ - единственная страна, которая обеспечила бесплатное тестирование и оказание медицинской помощи гражданам, заболевшим COVID-19.

(Обзор сделан на основе информации РИА Новости и открытых источников).

Как видно из обзора, в борьбе с эпидемией коронавируса задействовано много участников с различными возможностями и интересами: медицинские учреждения, научные и административные организации. Рационально согласовать их деятельность привычными методами планирования деятельности не всегда получается, чему накопилось много положительных и отрицательных примеров.

В качестве глобального примера можно вспомнить решение канцлера ФРГ Ангелы Меркель, которая в борьбе с коронавирусом решала о введении «пасхального локдауна», не учла мнение одного участника, а именно, граждан страны. И ей пришлось отменить локдаун и попросить прощения у граждан ФРГ.

А микропримером может служить попытки Управления организации обеспечения деятельности медицинских организаций. Департамента здравоохранения города Москвы спланировать свои разовые действия без полной информации о действиях многих активных участников борьбы с коронавирусом в стране. Приходилось оперативно вносить коррективы в свои действия и действия заинтересованных подведомственных организаций.

Результативное согласование деятельности многочисленных участников решения сложных проблем возможно с творческим использованием технологии Форсайта и его принципов.

Форсайт представляет собой новую технологию предвидения, посредством которой ведется обсуждение предполагаемых изменений в будущем, иначе говоря, осуществляется предвидение новых явлений и процессов, которые вызревают в сегодняшней деятельности.

Применение технологии Форсайта в медицине позволит не только выявить и проанализировать возможные альтернативы, но и выбрать наиболее результативные альтернативы.

Составляя перспективные планы деятельности учреждений здравоохранения необходимо учитывать позиции самых разнообразных структурных подразделений системы здравоохранения:

- федеральные и региональные органы и учреждения здравоохранения (государственная, бюджетная система здравоохранения);

- органы и учреждения государственной системы ОМС;

- частные медицинские учреждения и частнопрактикующие врачи (органы и учреждения ДМС и частного медицинского страхования);

- общественные, религиозные медицинские организации, фонды, организации и учреждения милосердия и благотворительности;

- позиции потребителей услуг учреждений здравоохранения должны учитываться не в последнюю очередь.

Принятию результативных решений специалистов надо учить и учить профессионально. Вводимые специализации Форсайта в некоторых вузовских специальностях не решают полностью проблемы управленческого профессионализма.

\section{Библиографический список}

1. Вишневский К. О. Форсайт как инструмент государственной инновационной политики: диссертация ... кандидата экономических наук: 08.00.05 / Вишневский Константин Олегович; [Место защиты: Моск. гос. ун-т им. М. В. Ломоносова. Экон. фак.].- Москва, 2013. - 170 с.: ил 
2. Вступительное слово Генерального директора на пресс брифинге по COVID-19 11 марта 2020 г.. Всемирная организация здравоохранения (11 марта 2020) Дата обращения: 27 июня 2020. Архивировано 15 июля 2020 года

3. Заявление по итогам второго совещания Комитета по чрезвычайной ситуации в соответствии с Международными медико-санитарными правилами, в связи со вспышкой заболевания, вызванного новым коронавирусом 2019 г. (nCoV). Всемирная организация здравоохранения (30 января 2020). Дата обращения: 16 июля 2020. Архивировано 24 июня 2020 года

4. Исаченко С.Н. Форсайт: зарубежный и российский опыт / С.Н.Исаченко, С. Н. Баюкова // Модели, системы, сети в экономике, технике, природе и обществе. 2014.- № 1 (9). - С. 30-34.

5. Ланских, А.Н. Опыт применения технологии форсайт. Оценка зарубежного опыта применения методологии форсайт / А.Н. Ланских // Бизнес в законе. - 2011. - № 5.- С. 231-233.

6. Наименование заболевания, вызванного коронавирусом (COVID-19), и вирусного возбудителя.Всемирная организация здравоохранения. Дата обращения: 27 июня 2020. Архивировано 24 июня 2020 года

7. Ранее неизвестный короновирус - Китай. Всемирная организация здравоохранения (12 января 2020). Дата обращения: 18 июля 2020. Архивировано 15 июля 2020 года.

8. Стерликов Ф.П. Стратегическое планирование и управление ресурсной логистикой медицинских учреждений. Обзор научных статей. Материалы Всероссийской конференции с международным участием. 2019.

9. Соколов, А. В. Форсайт: взгляд в будущее/ А. В. Соколов // Форсайт. - 2007. - № 1. - С.8-15.

10. Стерликов П.Ф., Стерликов Ф.П. Основные направления совершенствования финансового состояния компании. Сб.Экономические и правовые проблемы. М.: МГУТУ (ПКУ), 2019. С.56-69.

11. Стерликов Ф.П. К вопросу о собственности как юридической и экономической категории. Вопросы экономики и права, 2017, № 2. С. 12-15.

12. Стерликов Ф.П. Стратегическое планирование и управление ресурсной логистикой медицинских учреждений. Обзор научных статей. Материалы Всероссийской конференции с международным участием.

13. Третьяк, В.П.Форсайт как технология предвидения / В.П.Третьяк // Экономические стратегии.-2009.№ 8.- C. 52-59.

14. Chaolin Huang, Yeming Wang, Xingwang Li, Lili Ren, Jianping Zhao. Clinical features of patients infected with 2019 novel coronavirus in Wuhan, China (англ.)//Lancet-2020.- Vol. 395, iss. 10223.-P. 497-506. - ISSN 0140-6736. doi:10.1016/S0140-6736(20)30183-Архивировано16июня 2020 года.

15. Https://www.rbc.ru/business/19/03/2021/6053cfe79a7947a280eac562 